\title{
REVIEW
}

\section{Current data on predictive markers for anti- angiogenic therapy in thoracic tumours}

\author{
N. Reinmuth*,\#, M. Thomas*,\#, M. Meister*, P.A. Schnabel" and M. Kreuter ${ }^{+}$
}

\begin{abstract}
The fact that growth and spread of tumours are dependent on angiogenesis has led to the investigation of the role of anti-angiogenic agents in the therapeutic strategies for thoracic tumours such as nonsmall cell lung cancer or mesotheliomas. Since various angiogenic factors may contribute to the regulation of angiogenesis in the individual tumour, in the era of increasing amounts of clinically tested agents it is of utmost importance to properly select patients that may benefit from a specific therapy. Due to the complex nature of tumour angiogenesis, various biomarkers may be applicable. For example, the profile of activated angiogenic pathways in endothelial cells may be determined in order to make conclusions about the relevance of inhibiting a given pathway by a selected agent. Moreover, changes in protein expression in stromal and tumour cells, as well as structural alterations in the vasculature, may be used for predicting and monitoring the clinical effects of such a therapy. In this review, the current data from clinical studies evaluating predictive markers for anti-angiogenic agents in thoracic cancers are summarised. Besides giving clinical examples, the rationales for investigating various parameters based on pre-clinical studies are described.
\end{abstract}

KEYWORDS: Adhesion molecules, angiogenesis, circulating endothelial cells, vascular endothelial growth factor

\footnotetext{
A broad variety of therapeutic strategies targeting specific receptors or defined signalling pathways are being explored in clinical studies, including those of thoracic tumours, such as nonsmall cell lung cancer (NSCLC) and malignant mesothelioma. One such strategy is based on the widely accepted observation that, for tumour development and growth beyond a defined volume, the existence of a functional vessel system is mandatory. Therefore, most solid tumours would need the creation of new blood vessels for further growth and metastasis, which may be achieved by induction of endothelial cell sprouting from the pre-existing vasculature (so-called angiogenesis) [1-3]. Alternatively, the pre-existing vasculature may be co-opted by the tumour, which may have particular importance in lung cancer $[4,5]$. Finally, vasculogenesis has been shown to play an important role, at least in some tumour entities, by formation of new blood vessels from circulating endothelial precursor cells. These processes are regulated by multiple pro-angiogenic and anti-angiogenic factors that may be produced not only by tumour cells, but also by stromal cells [6]. However, to date, vascular endothelial growth factor (VEGF) is still
}

considered as one of the most potent angiogenic and endothelial cell survival factors.

Recently, two large clinical trials demonstrated efficacy of the anti-VEGF antibody bevacizumab in combination with a platinum-containing chemotherapy, in patients with advanced NSCLC of nonsquamous histology, resulting in US Food and Drug Administration approval for this setting [7, 8]. In the ECOG4599 study, a substantial clinical benefit for NSCLC patients treated with $15 \mathrm{mg} \cdot \mathrm{kg}^{-1}$ bevacizumab plus carboplatin and paclitaxel versus chemotherapy alone was seen (hazard ratio (HR) 0.66 for progression-free survival (PFS) with a median of 6.2 versus 4.5 months; HR 0.79 for overall survival with a median of 12.3 versus 10.3 months) [7]. These results were somewhat confirmed by another large phase III trial, in which NSCLC patients had an improved PFS with the addition of low-dose bevacizumab $\left(7.5 \mathrm{mg} \cdot \mathrm{kg}^{-1}\right.$; HR 0.75$)$ or high-dose bevacizumab $\left(15 \mathrm{mg} \cdot \mathrm{kg}^{-1}\right.$; HR 0.82) to standard chemotherapy with cisplatin and gemcitabine [8]. In the latter study, however, the median net gain of PFS was 0.6 and 0.4 months for the lowdose and the high-dose bevacizumab group, respectively. In both studies, there was a considerable

\section{AFFILIATIONS}

*Translational Research Unit, Thoraxklinik, University of Heidelberg,

\#Dept of Thoracic Oncology, Thoraxklinik, University of Heidelberg,

+Pneumology \& Respiratory Critical Care Medicine, Thoraxklinik,

University of Heidelberg,

"Institute of Pathology, University of Heidelberg, Heidelberg, Germany.

\section{CORRESPONDENCE}

N. Reinmuth

Dept of Internal Medicine, Thoracic Oncology, Clinic for Thoracic

Diseases

University of Heidelberg

Amalienstr. 5

D-69126 Heidelberg

Germany

E-mail: niels.reinmuth@thoraxklinik

heidelberg.de

Received:

May 062009

Accepted after revision:

March 102010 
subset of patients who did not respond or even experience progress under therapy $[8,9]$. Hence, predictive markers would be helpful in selecting the patients that may benefit from the therapy. Moreover, additional novel agents are being tested in clinical trials (table 1). As a likely future consequence, the clinician will need to decide which agents should be used for which patient.

As a hypothesis, since most novel agents such as bevacizumab are directed against a defined target, the expression of the putative target or consequences caused by its inhibition should be useful markers indicating responsiveness or resistance to the respective agent. An anti-angiogenic agent specifically targeting one selected pathway should exert the maximum effect in those tumours that critically depend on the given pathway. For example, if a tumour has upregulated angiogenesis by overexpressing VEGF, anti-VEGF therapy should impair new blood vessel formation in this respective tumour. Conversely, if analyses showed that the respective tumour has upregulated angiogenic pathways other than VEGF-dependent signalling, these results may indicate resistance to anti-VEGF therapy. Finally, anti-angiogenic therapy may lead to various escape mechanisms [17, 18] with the activation of alternative proangiogenic pathways. This may result in the necessity for repeated assessment of selected markers. Therefore, collection of cancer tissue samples before and, if possible, during or after therapy should be performed. In addition, less invasive methods may also be applicable, including measuring changes in protein concentrations (e.g. growth factors) in bodily fluids as surrogate markers for therapy. For example, blood plasma levels of VEGF were significantly increased by vascular endothelial growth factor receptor (VEGFR)-2 blockade in mice and were proposed as a surrogate marker for anti-VEGFR-2 therapy [19].

\section{PREDICTIVE AND PROGNOSTIC MARKERS}

A prognostic factor is a patient or tumour characteristic that is indicative of the biology of the tumour and correlates with the patient's prognosis regardless of the treatment [20,21]. In contrast, a predictive marker is a patient or tumour characteristic that should give information whether the patient is likely to benefit from a given treatment. Hence, a prognostic factor determines the effect of the tumour on the patient and is best determined in untreated patients, while a predictive factor determines the effect of the treatment on the tumour [20].

However, most factors show mixed prognostic and predictive associations. For example, markers of proliferation, such as Ki67 , that show strong prognostic effects are also predictive of greater response to most chemotherapy regimes [21]. Moreover, and as discussed below, VEGF protein expression has been identified as a prognostic factor in NSCLC $[22,23]$ but may also harbour predictive value of increased response to anti-VEGF therapy, as indicated by results of the ECOG4599 study [10]. Several molecular factors that are described in the following have been linked with lung cancer prognosis. Still, the following review will focus on current attempts to establish predictive markers for anti-angiogenic therapies.

To investigate whether a biomarker is predictive for a given treatment, clinical trials should include molecular analyses of patient-derived material. The final goal would be the identification of a biomarker that is helpful in clinical decision

TABLE 1 Anti-angiogenic agents approved or in development for treatment of patients with lung cancer

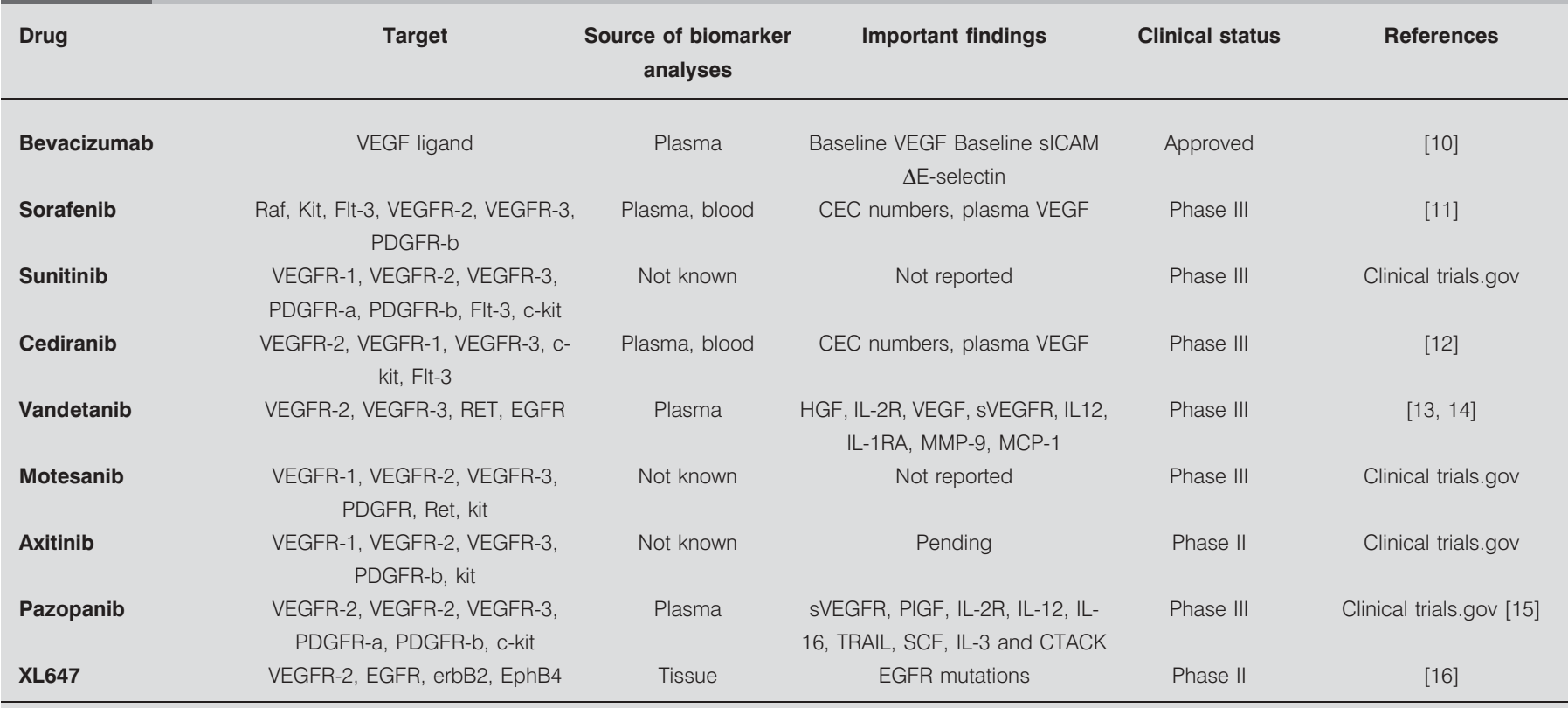

VEGF: vascular endothelial growth factor; sICAM: soluble intercellular adhesion molecule; VEGFR: vascular endothelial growth factor receptor; PDGFR: platelet-derived growth factor receptor; CEC: circulating endothelial cell; EGFR: epidermal growth factor receptor; HGF: human growth factor; IL: interleukin; IL-2R: IL-2 receptor; SVEGFR: soluble VEGFR; IL-IRA: IL-1 receptor antagonist; MMP: matrix metalloprotease; MCP: monocyte chemotactic protein; PIGF: placenta growth factor; TRAIL: tumour necrosis factor-related apoptosis-inducing ligand; SCF: stem cell factor; CTACK: cutaneous T-cell attracting chemokine; EphB4: Ephrin B4. 
making. However, the search for biomarkers has just begun. Even the few large clinical trials published to date that included molecular analyses have yielded a confusing variety of potential markers. The following review should give a broad overview about the rationales of biomarker testing depending on the respective target.

\section{CHALLENGES IN IDENTIFYING BIOMARKERS}

The most often explored types of biomarkers for antiangiogenic therapy include investigation of tumour-derived tissue and assessment of circulating markers that are detected by peripheral blood analyses. However, although results from preclinical studies have generated promising candidates for predictive biomarkers, important challenges remain for their translation into practice. For example, the technology used to measure various biomarkers has not been standardised. Hence, the selection of high-quality reagents, optimal methodology and processing using standardised protocols need to be clearly defined. Variables such as storage periods for cut tissue sections, the type of fixative used and the choice of markers may impact the quality of the results. Moreover, there is no consensus on the interpretation and scoring of the data that are generated by these methods. As discussed below, current studies have yielded sometimes conflicting results that were at least partly due to different methodologies. However, attempts for standardising procedures such as assessment of microvessel density (MVD) are ongoing [24]. Also, the selection of the appropriate clinical trial design for biomarker identification and validation is mandatory as recently described $[25,26]$. Moreover, due to the heterogeneous and dynamic nature of angiogenesis, the angiogenic profile of a tumour might change with cancer progression and duration of treatment [27]. Thus, a biopsy taken before first treatment might not reflect the biology before second or third treatment. However, re-assessment of tissue marker may be difficult since an additional bronchoscopy or computed tomography (CT) scan guided biopsy would be necessary that harbour several procedure-related risks. Hence, different types of biomarkers (e.g. imaging and circulating markers) may have to be combined to yield a "composite biomarker" to make more robust predictions [27]. Finally, one characteristic of most clinical studies was that biomarker investigations were performed on a rather small percentage of the patients included in a large series, which questions the representativeness of the findings.

\section{MARKERS IN TUMOUR BIOPSIES}

\section{Microvessel density}

Most clinical studies investigating the prevalence and prognostic impact of angiogenesis in solid tumours have used tissue samples and counted microvessels after performing immunohistochemistry. Two methods of counting microvessels have been widely used: the density method, in which all vessel areas of high vessel concentrations are counted [28], and the Chalkley method, using a graticule counting the number of vessels touching 25 random point readings, which resembles a relative area estimate rather than a true vessel count [29]. Due to different methodologies, an international consensus to assess the different angiogenic parameters in solid tumours including standard staining protocols and evaluation criteria has been published [24].
For NSCLC, conflicting results have been reported on the prognostic importance of MVD in various subsets of patients [4, 30-32]. One meta-analysis concluded that MVD seems to correlate as a prognostic factor with reduced survival in NSCLC independently of assessment of factor VIII, CD34 or CD31 positivity [33]. In contrast, another meta-analysis contradicted these results, partly due to different methods and statistical analyses [34]. Both meta-analyses reported considerable variations in the results among the individual studies that were, at least in part, due to heterogeneous methodologies used to stain and count microvessels [33-35].

As a hypothesis, MVD may also hold valuable information on the response of a tumour to anti-angiogenic therapy and, therefore, be used as a potential predictive marker [36, 37]. However, in 312 analysed of a total of 813 colorectal cancer patients treated with chemotherapy with or without bevacizumab, the pre-therapeutic MVD was not a significant indicator for a putative benefit of bevacizumab addition [38]. Still, no clinical study known to the authors investigated the impact of anti-angiogenic therapy on MVD in NSCLC. Since most NSCLC patients treated with anti-angiogenic therapy are stage IV patients, tumour histology is most often analysed on small biopsies derived from bronchoscopy or CT scan-guided biopsy. It may be questionable whether the size of these tissue samples is representative for the whole tumour [39]. Moreover, a considerable subset of lung tumours seems to co-opt the preexisting vasculature with possible implications for prognosis and response to anti-angiogenic therapy [4]. Finally, antiangiogenic therapy may not only affect tumour vessels but also the normal vasculature [40]. As a hypothesis, healthy tissue may therefore be used for monitoring anti-angiogenic therapy similar to clinical studies using anti-endothelial growth factor receptor (EGFR) agents [41]. Alternatively, the vessel density and intra-tumoural blood supply may be estimated using radiological techniques such as contrast enhanced magnetic resonance imaging or positron emission tomography, which have been recently reviewed by others [42].

\section{VEGF and VEGFR expression of tumour, endothelial and other stromal cells}

VEGF expression and VEGFR activation status in endothelial cells may be predictive for the therapeutic response to antiVEGF-directed therapy. As summarised in an extensive metaanalysis, VEGF expression or overexpression has been reported in $\sim 60 \%$ of NSCLC [22]. Most studies have indicated a significant positive correlation between VEGF immunoreactivity and tumour vascularity [22, 43]. Also, both high VEGF-A and VEGF-C protein expression have been associated with poor NSCLC survival in the majority of clinical studies [22, 23]. In addition, VEGFR expression has been documented in endothelial, stromal and even tumour cells [44]. However, the clinical significance of these findings is unknown. Preclinical data suggest a possible correlation of endothelial cell expression of phosphorylated VEGFR with response to VEGFR inhibitors [45]. To date, however, there are no clinical studies that have evaluated VEGF expression relative to response to anti-VEGF agents in lung cancer. In a clinical trial of 278 patients with metastatic colon cancer, neither epithelial and stromal VEGF expression nor MVD were predictors of benefit from the addition of bevacizumab to fluorouracil-based 
therapy [38]. Alternatively, intracellular pathways or expression of other growth factors influencing VEGFR-dependent signalling may be useful as potential biomarkers for antiVEGFR2-directed therapies [46, 47]. Data from clinical NSCLC studies are pending.

\section{CIRCULATING MARKERS}

\section{Circulating angiogenic markers}

To date, most data on potential predictive markers for antiangiogenic therapy have been generated by measuring circulating angiogenic proteins in serum or plasma. Preclinical studies have brought much insight into the function of these factors. However, whether the serum concentration of these factors or changes upon therapy initiation may hold predictive value remains undetermined. Since most anti-angiogenic agents in clinical studies focus on targeting the VEGFR signalling pathway, this pathway has been explored most extensively.

VEGF belongs to a larger family consisting of six VEGF molecules, VEGF-A to -E and the placental growth factor (PIGF), and three VEGF receptors, VEGFR-1 to -3 [2, 48]. In mice bearing human VEGF overexpressing tumours, treatment for 7 days with sunitinib, a small-molecule inhibitor of VEGF and platelet-derived growth factor (PDGF) receptor tyrosine kinases (RTKs), led to a dose-dependent increase in both circulating mouse and tumour-specific VEGF plasma levels as determined by species-specific ELISA tests. Conversely, the opposite cyclical pattern was seen with circulating soluble VEGFR-2 (sVEGFR-2), which was possibly mediated by VEGF-mediated VEGFR-2 downregulation [49]. Interestingly, elevations of VEGF and decreases in sVEGFR-2 were also noticed in normal mice free of any tumour treated with sunitinib, indicating that these molecular changes are a systemic response to drug treatment and that the changes occur maximally in the optimal antitumour dose range [19].

Similar to preclinical data, cancer patients treated with various anti-VEGFR inhibitors showed increased levels of plasma VEGF and decreased levels of sVEGFR-2 (table 2). In the ECOG 4599 study, a phase II/phase III trial randomising 878 patients with advanced NSCLC to carboplatin and paclitaxel with or without bevacizumab, patients with high pre-treatment VEGF levels were more likely to respond to bevacizumab-containing therapy, but this was not predictive of survival [10]. In addition, serum VEGF levels were also indicative for prognosis. Patients with a low VEGF level had a better PFS (median 6.0 months) compared with patients with a high level (median 4.5 months; $\mathrm{p}=0.04$ ) [10]. However, only 166 samples from a total of 878 patients were available for these ELISA measurements.

In an exploratory retrospective analysis, the predictive value of pretreatment circulating VEGF levels was analysed in three randomised phase II studies including vandetanib, a VEGFR, EGFR and RET RTK inhibitor, either as a monotherapy or in combination with chemotherapy for advanced NSCLC [13]. Patients with baseline VEGF values within the ELISA reference range for healthy subjects had a superior PFS when treated either with $300 \mathrm{mg} \cdot \mathrm{day}^{-1}$ vandetanib versus gefitinib (HR 0.55; $\mathrm{p}=0.01$ ) or with a combination of $100 \mathrm{mg} \cdot \mathrm{day}^{-1}$ vandetanib and docetaxel versus docetaxel alone (HR 0.25; $\mathrm{p}=0.01$ ). However, there was no significant difference in PFS among patients with low baseline plasma VEGF who received docetaxel and
$300 \mathrm{mg} \cdot$ day $^{-1}$ vandetanib versus docetaxel alone (HR 0.66; $p=0.33)$. Similarly, low baseline VEGF was not predictive for a different PFS in patients treated with carboplatin-paclitaxel and $300 \mathrm{mg} \cdot$ day $^{-1}$ vandetanib compared with carboplatinpaclitaxel alone (HR 0.72; $\mathrm{p}=0.29)$. Moreover, in a patient subset, multiplex analyses of plasma levels of 35 angiogenic factors were done. Several factors were of prognostic value, whereas low human growth factor (HGF) and interleukin-2R levels were predictive of benefit only in the vandetanib monotherapy arm [14].

Similar to NSCLC patients, limited data are available on the predictive value of circulating VEGF levels in patients with malignant mesothelioma. In a multi-centre, placebo-controlled randomised phase II trial, 108 mesothelioma patients were treated with the combination of cisplatin and gemcitabine with or without bevacizumab. In patients who received bevacizumab, baseline VEGF levels at or below the median were correlated with a significantly improved PFS $(p=0.043)$ and overall survival $(p=0.028)$ [52]. In contrast, higher baseline plasma VEGF levels were of prognostic value and were associated with shorter PFS $(p=0.02)$ and overall survival $(p=0.0066)$. These results may suggest that anti-VEGF therapy could benefit some patients with malignant mesothelioma; however, confirmative studies are needed. In another phase II study, 51 patients with malignant mesothelioma were treated with sorafenib, an inhibitor of VEGFR2 and PDGF receptor-b [53]. Correlative studies including expression of p-ERK 1/2, baseline VEGF and PDGF levels have been performed, but results have not yet been reported.

\section{Circulating adhesion molecules}

For every anti-angiogenic agent, the final aim is modulating the function and survival of endothelial cells, e.g. by inhibiting VEGFR activation. For proper endothelial cell functions, including angiogenesis and maintenance of the existing blood vessels, endothelial cells must adhere firmly to one another and to the extracellular matrix (ECM). Consequently, various cell adhesion molecule (CAM) families with characteristic structural patterns have been described: the cadherins, the selectins, the integrins and the immunoglobulin-CAM superfamily [54, 55]. Moreover, several CAMs exist that do not share any of the structural patterns of the four CAM families, such as the epithelial CAMs. CAMs may be shed upon stimulation by various angiogenic factors into the circulation, where they may act as markers of activated or damaged endothelial cells [56]. Hence, selected CAMs have been investigated as potential markers monitoring anti-angiogenic therapies.

Endothelial (E)-selectin is synthesised by endothelial cells in response to inflammatory stimuli and involved in the recruitment of leukocytes and tumour progression $[54,57]$. Expression levels of soluble E-selectin in the peripheral blood often correlate with the duration and severity of inflammatory diseases and have been detected in supernatants of cytokine-activated endothelial cells in vitro [58]. In NSCLC patients, however, the prevalence of elevated serum E-selectin levels has been controversially published in small series of lung cancer patients compared to patients with benign lung diseases and healthy volunteers [59, 60]. The aforementioned ECOG4599 study analysed E-selectin as a potential predictive marker in peripheral blood samples from 149 of 878 total patients included in 
TABLE 2 Predictive value of pre-treatment vascular endothelial growth factor (VEGF) plasma levels

\begin{tabular}{|c|c|c|c|c|c|c|c|c|}
\hline \multirow[t]{2}{*}{ Treatment and dose } & \multirow[t]{2}{*}{ Patients ${ }^{\#}$} & \multirow[t]{2}{*}{ Tumour } & \multirow[t]{2}{*}{ Subgroup } & \multicolumn{3}{|c|}{ Correlation } & \multirow{2}{*}{$\begin{array}{c}\text { Change during } \\
\text { therapy }\end{array}$} & \multirow[t]{2}{*}{ References } \\
\hline & & & & $\mathbf{R R}$ & PFS & os & & \\
\hline $\begin{array}{l}\text { ABT-869 } \\
0.1 \text { to } 0.3 \mathrm{mg} \cdot \mathrm{kg}^{-1} \cdot \mathrm{day}^{-1}\end{array}$ & 33 & Various & VEGF-A & ND & ND & ND & INC & {$[50]$} \\
\hline $\begin{array}{l}\text { Bevacizumab } \\
\left(15 \mathrm{mg} \cdot \mathrm{kg}^{-1}\right)+\mathrm{PC}\end{array}$ & $166 / 878$ & NSCLC & VEGF-A $<35.7 \mathrm{pg} \cdot \mathrm{mL}^{-1}$ & NC & INC & NC & ND & {$[10]$} \\
\hline $\begin{array}{c}\mathrm{GC} \pm \text { bevacizumab } \\
15 \mathrm{mg} \cdot \mathrm{kg}^{-1}\end{array}$ & $56 / 108$ & MM & VEGF-A $<$ median & ND & INC & INC & ND & [52] \\
\hline $\begin{array}{l}\text { Vandetanib } 300 \mathrm{mg} \cdot \mathrm{d}^{-1} \\
\text { versus PC }\end{array}$ & $91 / 113$ & NSCLC & VEGF-A $>707 \mathrm{pg} \cdot \mathrm{mL}^{-1}$ & ND & DEC (trend) & NC & ND & [13] \\
\hline $\begin{array}{c}\mathrm{PC} \pm \text { vandetanib } \\
300 \mathrm{mg}^{- \text {day }^{-1}}\end{array}$ & $86 / 108$ & NSCLC & VEGF-A $<707 \mathrm{pg} \cdot \mathrm{mL}^{-1}$ & ND & NC & NC & ND & [13] \\
\hline $\begin{array}{l}\text { Docetaxel } \pm \text { vandetanib } \\
300 \mathrm{mg} \cdot \text { day }^{-1}\end{array}$ & $45 / 85$ & NSCLC & $\begin{array}{l}\text { Low VEGF-A } \\
<115 \mathrm{pg} \cdot \mathrm{mL}^{-1}\end{array}$ & ND & NC & INC & ND & [13] \\
\hline $\begin{array}{l}\text { Docetaxel } \pm \text { vandetanib } \\
100 \mathrm{mg}\end{array}$ & $44 / 83$ & NSCLC & $\begin{array}{l}\text { Low VEGF-A } \\
<115 \mathrm{pg} \cdot \mathrm{mL}^{-1}\end{array}$ & ND & INC & INC & ND & {$[13]$} \\
\hline Pazopanib 800 mg q.o.d. & 19 & NSCLC & sVEGFR-2 & ND & ND & ND & DEC & [15] \\
\hline
\end{tabular}

RR: response rate; PFS; progression-free survival; OS: overall survival; ABT-869: inhibitor of vascular endothelial growth factor receptors (VEGFR) 1-3 and plateletderived growth factor receptors (PDGFR); Bevacizumab: VEGF antibody, receptor tyrosine kinase inhibitors; E7080: receptor tyrosine kinase inhibitors of VEGFR-2. PDGFRs, fibroblast growth factor receptors, c-kit; GC: gemcitabine and cisplatin; Vandetanib: antagonist of VEGFR-2, epidermal growth factor receptor, and inhibitor of RET; PC: paclitaxel and carboplatin; pazopanib: VEGFR, PDGFR and c-kit inhibitor; INC: increased/superior; DEC: decreased/inferior; ND: not determined; NC: no change; MM: malignant mesothelioma; NSCLC: nonsmall cell lung cancer. ${ }^{\#}$ : number of patients (or tumours) investigated/total number of patients.

the study. Interestingly, E-selectin showed a significant decrease over 7 weeks of treatment, while the magnitude of the change was not significantly different between treatment arms [10]. Patients treated with bevacizumab combined chemotherapy and exhibiting a drop of E-selectin of less than $5.35 \mathrm{ng} \cdot \mathrm{mL}^{-1}$ had a significant longer overall survival (HR 1.98, 95\% CI 1.1-3.57; $\mathrm{p}=0.02)$ compared with patients treated with chemotherapy alone.

Another class of important CAMs is the immunoglobulin superfamily, including intercellular adhesion molecule (ICAM)-1. ICAM-1 is present on various cell types, including resting endothelial cells [61], where it is involved in the attachment and subsequent trans-endothelial migration of leukocytes to sites of inflammation. Activated endothelial cells produce large amounts of membrane ICAM-1 and shed the soluble form (sICAM-1), which itself may promote angiogenesis and tumour growth [62]. While elevated sICAM-1 levels have been reported to be significantly higher in NSCLC patients compared with controls and to be correlated with more advanced disease [63], other studies suggest that sICAM-1 levels do not necessarily reflect the extent of membrane expression and may be independently regulated [61]. Still, sICAM-1 has been investigated in the context of anti-angiogenic therapy. The ECOG4599 study identified low baseline ICAM-levels as a significant predictive factor for improved PFS (HR 2.14, 95\% CI 1.31-3.48) but not overall survival
(HR 1.39, 95\% CI 0.84-2.3) when bevacizumab was added to cytotoxic therapy [10].

Cadherins represent another major CAM family. Based on sequence comparison they can be divided into different subfamilies, among which are the classical type I cadherins, such as E- and N-cadherin, and the type II cadherins [55, 64, 65]. Vascular endothelial (VE)-cadherin, a type II cadherin, is a strictly endothelial specific adhesion molecule and seems to be of critical importance for the maintenance and control of endothelial cell contacts [55]. In addition to its adhesive functions, VEcadherin regulates various cellular processes, such as cell proliferation and apoptosis, and modulates VEGFR-2 function. Mice deficient in VE-cadherin died at mid-gestation from vascular malformations [66]. Because of the fundamental role in regulating angiogenesis, VE-cadherin may be an interesting marker for analysis in anti-angiogenic therapeutic trials; however, results from clinical studies are pending.

Finally, integrins are a large family of cell surface receptors encoded by $\alpha$ and $\beta$ chains, which mediate cell-ECM as well as cell-cell interactions [67]. In tumours including NSCLC, integrins are mediators of invasion and metastasis through ECM interaction [68]. Particularly interesting may be integrin $\alpha v \beta 3$ that is well expressed in proliferating vessels but not as much in normal non-proliferating vessels [69]. Still, while $\alpha v \beta 3$ 
integrin has been evaluated as a target in preclinical and clinical studies $[70,71]$ and is being elucidated for molecular imaging of angiogenesis using $\alpha v \beta 3$ targeted nanoparticles, its use as a potential biomarker for anti-angiogenic therapy remains speculative.

\section{Circulating endothelial cells}

Besides angiogenesis and co-option of pre-existing blood vessels, vasculogenesis as the de novo synthesis of new blood vessels by endothelial progenitor cells (EPCs) has been postulated to play an important role beyond embryonic development (fig. 1) [73]. Starting in 1997, various groups reported on cultivation of CD34+ progenitor cells from adults ex vivo $[74,75]$ that may contribute to re-endothelialisation of grafts and vascular prostheses [75, 76]. While the incorporation of EPCs has been demonstrated in tumour vascularisation [73], the significance of this finding has been debated. In healthy individuals, EPC numbers are low ([77] and unpublished results), however, their numbers tend to increase following vascular injury and myocardial infarction [78-80]. In various studies, conflicting data have been reported on the quantification of EPCs in tumour patients, including NSCLC, in comparison to healthy controls [77, 81]. Still, the importance of EPCs may be increased by the release of pro-angiogenic factors such as VEGF and HGF with a possible prognostic impact as demonstrated in a series of 53 NSCLC patients [81].
Furthermore, anti-vascular therapy may alter the numbers of EPCs, which may hold predictive value for therapy response. Treatment of tumour-bearing mice with vascular disrupting agents led to an acute mobilisation of circulating EPCs as determined by VEGFR-2, CD13 and CD117 positivity [82]. Conclusively, there has been interest in evaluating the role of EPCs as markers for drug therapy monitoring [83].

In addition to EPCs, the presence of circulating endothelial cells (CECs) in the peripheral blood that are shed off the vessel wall have been considered to be a promising surrogate marker for vascular damage. In healthy individuals, CECs are rarely detected, while increased numbers have been documented in various cancer and lymphoma patients [77, 84]. Breast cancer studies suggested that CECs are a prognostic indicator for patients receiving metronomic chemotherapy [85]. Moreover, in vivo studies described a change in CEC levels upon antiangiogenic therapy. Lewis lung carcinoma-bearing mice had an increase in CECs but not EPCs after 3 days of treatment with the EGFR and VEGFR-2 inhibitor vandetanib that preceded reduction in tumour volume [86].

However, controversy exists with respect to identification of EPCs and CECs. Since marker profiles have been generated from cultivated mononuclear cells ex vivo (fig. 2), the phenotype of these cells may have changed due to culture conditions, as indicated by several groups including preliminary data from

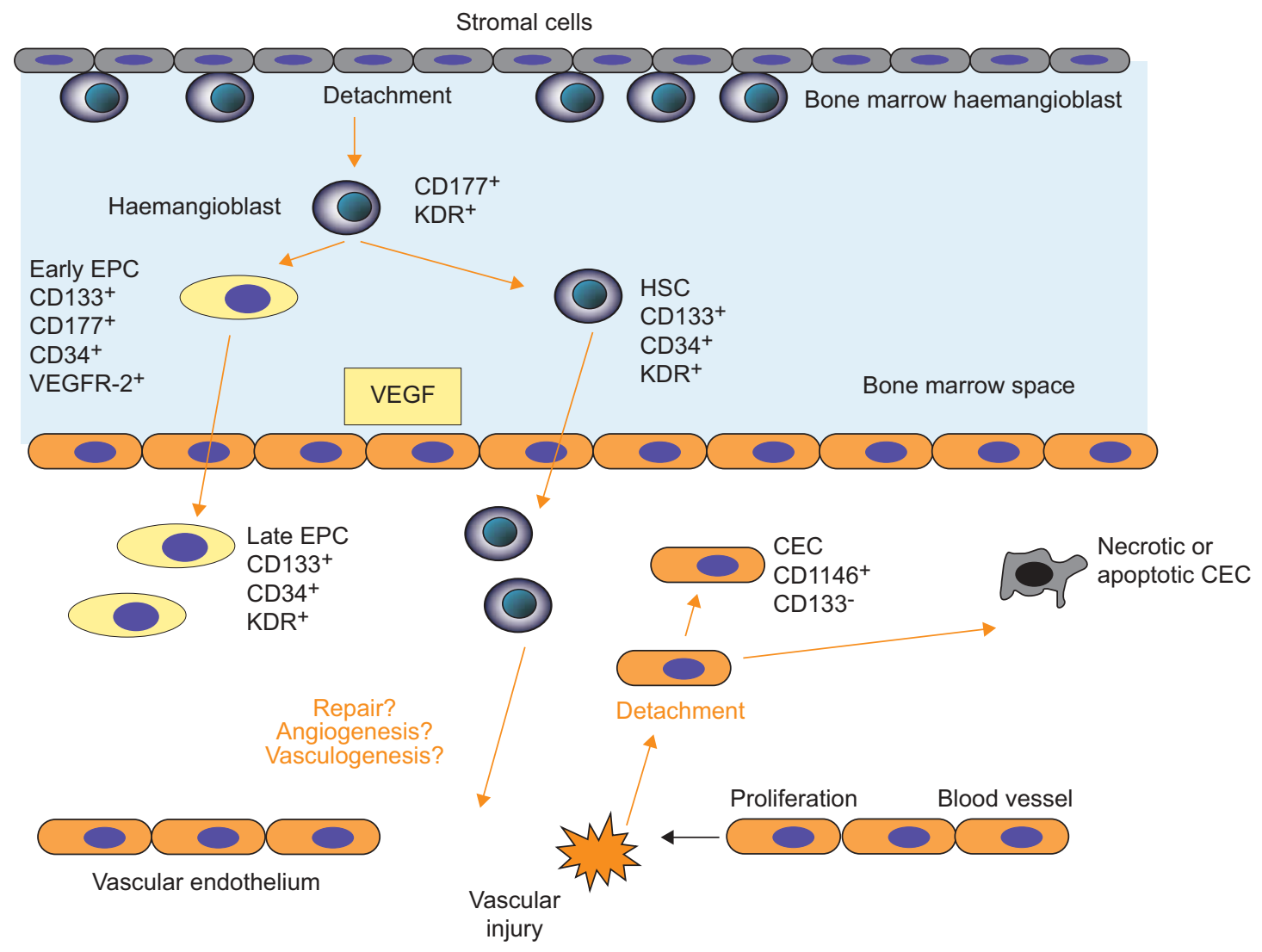

FIGURE 1. Scheme of origin and differentiation of endothelial progenitor cells (EPC). Haematopoietic stem cell (HSC)-derived EPC and circulating endothelial cells (CEC) can be found in vascular damage, repair and angiogenesis, and are characterised by different marker expression profiles. VEGF: vascular endothelial growth factor; VEGFR-2: vascular endothelial growth factor receptor-2; VEGFR-2/KDR: kinase insert domain receptor. Adapted from [72] with permission from the publisher. 

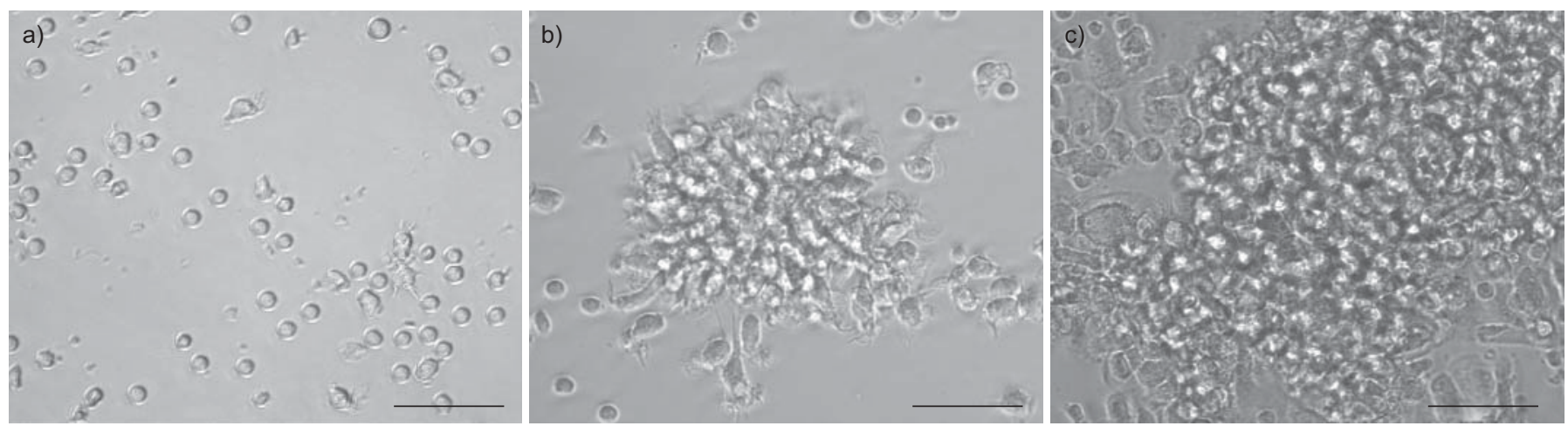

FIGURE 2. Outgrowth of endothelial precursor cells (EPCs) from the peripheral blood. After depletion of CD34+ cells, peripheral blood cells were cultured on to gelatin coated flasks. Within 7 days, colonies were formed by EPC-derived endothelial cells. Characteristic pictures of EPC-derived endothelial cells-forming colonies after a) 1 day, b) 5 and c) 7 days of culture are shown (magnification $\times 200$ ). Scale bar $=100 \mu \mathrm{m}$.

our own laboratory ([80, 87] and unpublished results). Initially, EPCs were defined as cells positive for both haematopoietic stem cell markers such as CD34 and endothelial markers such as VEGFR2 [75]. However, since CD34 is also expressed on mature endothelial cells to a somewhat lower level, assessment of additional markers, such as CD133 positivity, that seem to be exclusively expressed on haematopoietic stem cells is mandatory [80]. To date, most authors coincide that CD133/VEGFR2 positive cells represent a population with endothelial progenitor capacity $[72,80]$. Similarly, different marker expression patterns have been described for CECs. Most groups require detection of endothelial cell markers, such as CD31 or CD34, in the absence of CD133 expression [72, 85]. Also, results generated by flow cytometry analyses used by most authors may be influenced by several factors, such as separation of mononuclear cells, washing and centrifugation steps, the panel of monoclonal antibodies and the lack of standardisation of gating techniques. Hence, various improvements have been attempted, including specific and nonspecific antibody combinations [88] and isolation by size using a defined filter for isolation of EPCs instead of centrifugation of blood samples [89].

Conclusively, while many questions regarding the origin and characterisation of circulating endothelial cells remain to be addressed, these cells may be still promising predictive markers for anti-angiogenic cancer therapy which have not been addressed in large clinical studies.

\section{FUTURE DIRECTIONS}

As new therapeutic options emerge, it is desirable to use our increasing knowledge of tumour molecular biology to optimise and individualise cancer therapy. However, a careful design of appropriate clinical trials for assessing the utility of markers is mandatory and has been described elsewhere [21, 25, 90]. Besides the parameters described above, various other factors may hold predictive value for anti-angiogenic therapy. For example, a host of other angiogenic factors also contribute to blood vessel formation in a tumour. Besides VEGF, which is known as a key factor for regulating angiogenesis, other growth factors, such as PDGF, basic fibroblast growth factor and angiopoietins, as well as various CAMs, have also been shown to be of importance in various tumour models. In a preclinical study, a set of six genes were identified to be selectively overexpressed in tumour-derived endothelial cells [91]. Hence, it may be reasonable to screen tumour or blood samples for several key regulating molecules to identify on which angiogenic factor the tumour is most likely dependent.

Moreover, vascular remodelling that affects vascular stability may be an important determinant for response of endothelial cells to anti-vascular therapy. In this process, the cross talk of endothelial cells with other stromal cells such as pericytes, vascular smooth muscle cells and fibroblasts plays a fundamental role [92, 93]. The importance of pericytes has been clearly demonstrated in PDGF-B deficient mice, leading to defective blood vessel development [94]. Therefore, in addition to being a prognostic marker [4], determination of perivascular cell coverage may be a predictive marker for the vulnerability of the vessels to anti-angiogenic and anti-vascular agents [95].

It is likely that a combination of markers or "signature" might prove to be of greater prognostic and predictive value than a single factor. Even though we may not be able to characterise every patient in the future, the primary aim would be to define subgroups with exceptionally improved or decreased response to a selected agent. With the number of biomarker studies increasing, hopefully, this will lead us to increasing numbers of well characterised patient subgroups which may result in improved therapeutic planning and an extended overall survival.

\section{STATEMENT OF INTEREST}

None declared.

\section{REFERENCES}

1 Yano S, Nishioka Y, Goto $\mathrm{H}$, et al. Molecular mechanisms of angiogenesis in non-small cell lung cancer, and therapeutics targeting related molecules. Cancer Sci 2003; 94: 479-485.

2 Hicklin DJ, Ellis LM. Role of the vascular endothelial growth factor pathway in tumor growth and angiogenesis. J Clin Oncol 2005; 23: 1011-1027.

3 Kerbel RS. Tumor angiogenesis. N Engl J Med 2008; 358: 2039-2049.

4 Reinmuth N, Piegelbrock E, Raedel M, et al. Prognostic significance of vessel architecture and vascular stability in non-small cell lung cancer. Lung Cancer 2007; 55: 53-60.

5 Offersen BV, Pfeiffer P, Hamilton-Dutoit S, et al. Patterns of angiogenesis in nonsmall-cell lung carcinoma. Cancer 2001; 91: 1500-1509. 
6 Scappaticci FA. Mechanisms and future directions for angiogenesis-based cancer therapies. J Clin Oncol 2002; 20: 3906-3927.

7 Sandler A, Gray R, Perry MC, et al. Paclitaxel-carboplatin alone or with bevacizumab for non-small-cell lung cancer. $N$ Engl J Med 2006; 355: 2542-2550.

8 Reck M, von Pawel J, Zatloukal P, et al. Phase III trial of cisplatin plus gemcitabine with either placebo or bevacizumab as first-line therapy for nonsquamous non-small-cell lung cancer: AVAil. J Clin Oncol 2009; 27: 1227-1234.

9 Ramalingam SS, Dahlberg SE, Langer CJ, et al. Outcomes for elderly, advanced-stage non small-cell lung cancer patients treated with bevacizumab in combination with carboplatin and paclitaxel: analysis of Eastern Cooperative Oncology Group Trial 4599. J Clin Oncol 2008; 26: 60-65.

10 Dowlati A, Gray R, Sandler AB, et al. Cell adhesion molecules, vascular endothelial growth factor, and basic fibroblast growth factor in patients with non-small cell lung cancer treated with chemotherapy with or without bevacizumab - an Eastern Cooperative Oncology Group Study. Clin Cancer Res 2008; 14: 1407-1412.

11 Lind JS, Dingemans AC, Groen HJ, et al. A phase II study of erlotinib and sorafenib in chemotherapy-naive patients with locally advanced/metastatic non-small cell lung cancer (NSCLC). J Clin Oncol 2009; 27: A8018.

12 Ramalingam SS, Mack PC, Vokes EE, et al. Cediranib (AZD2171) for the treatment of recurrent small cell lung cancer (SCLC): A California Consortium phase II study (NCI \# 7097). J Clin Oncol 2008; 26: A8078.

13 Hanrahan EO, Ryan AJ, Mann $\mathrm{H}$, et al. Baseline vascular endothelial growth factor concentration as a potential predictive marker of benefit from vandetanib in non-small cell lung cancer. Clin Cancer Res 2009; 15: 3600-3609.

14 Hanrahan EO, Lin HY, Du DZ, et al. Correlative analyses of plasma cytokine/angiogenic factor $(\mathrm{C} / \mathrm{AF})$ profile, gender and outcome in a randomized, three-arm, phase II trial of first-line vandetanib (VAN) and/or carboplatin plus paclitaxel (CP) for advanced non-small cell lung cancer (NSCLC). J Clin Oncol 2007; 25: A7593.

15 Nikolinakos P, Altorki N, Guarino M, et al. Analyses of plasma cytokine/angiogenic factors (C/AFs) profile during preoperative treatment with pazopanib (GW786034) in early-stage non-small cell lung cancer. J Clin Oncol 2008; 26: A7568.

16 Rizvi NA, Kris MG, Miller VA, et al. Activity of XL647 in clinically selected NSCLC patients (pts) enriched for the presence of EGFR mutations: Results from Phase 2. J Clin Oncol 2008; 26: A8053.

17 Paez-Ribes M, Allen E, Hudock J, et al. Antiangiogenic therapy elicits malignant progression of tumors to increased local invasion and distant metastasis. Cancer Cell 2009; 15: 220-231.

18 Casanovas O, Hicklin DJ, Bergers G, et al. Drug resistance by evasion of antiangiogenic targeting of VEGF signaling in late-stage pancreatic islet tumors. Cancer Cell 2005; 8: 299-309.

19 Ebos JM, Lee CR, Christensen JG, et al. Multiple circulating proangiogenic factors induced by sunitinib malate are tumorindependent and correlate with antitumor efficacy. Proc Natl Acad Sci USA 2007; 104: 17069-17074.

20 Coate LE, John T, Tsao MS, et al. Molecular predictive and prognostic markers in non-small-cell lung cancer. Lancet Oncol 2009; 10: 1001-1010.

21 Dowsett M, Dunbier AK. Emerging biomarkers and new understanding of traditional markers in personalized therapy for breast cancer. Clin Cancer Res 2008; 14: 8019-8026.

22 Zhu CQ, Shih W, Ling CH, et al. Immunohistochemical markers of prognosis in non-small cell lung cancer: a review and proposal for a multiphase approach to marker evaluation. J Clin Pathol 2006; 59: 790-800.
23 Delmotte $\mathrm{P}$, Martin B, Paesmans M, et al. VEGF et survie des patients atteints d'un cancer pulmonaire: revue systématique avec méta-analyse [VEGF and survival of patients with lung cancer: a systematic literature review and meta-analysis]. Rev Mal Respir 2002; 19: 577-584.

24 Vermeulen PB, Gasparini G, Fox SB, et al. Second international consensus on the methodology and criteria of evaluation of angiogenesis quantification in solid human tumours. Eur J Cancer 2002; 38: 1564-1579.

25 Sargent DJ, Conley BA, Allegra C, et al. Clinical trial designs for predictive marker validation in cancer treatment trials. J Clin Oncol 2005; 23: 2020-2027.

26 Mandrekar SJ, Sargent DJ. Clinical trial designs for predictive biomarker validation: theoretical considerations and practical challenges. J Clin Oncol 2009; 27: 4027-4034.

27 Emerging Paradigms and Potential Biomarkers of Response and Resistance in Antiangiogenic Therapy of Cancer. In: Educational Book ASCO. Alexandria, Americal Society of Clinical Oncology, 2009; pp. 716-721.

28 Weidner N, Semple JP, Welch WR, et al. Tumor angiogenesis and metastasis - correlation in invasive breast carcinoma. N Engl J Med 1991; 324: 1-8.

29 Fox SB, Leek RD, Weekes MP, et al. Quantitation and prognostic value of breast cancer angiogenesis: comparison of microvessel density, Chalkley count, and computer image analysis. J Pathol 1995; 177: 275-283.

30 Kojima H, Shijubo N, Abe S. Thymidine phosphorylase and vascular endothelial growth factor in patients with stage I lung adenocarcinoma. Cancer 2002; 94: 1083-1093.

31 Pastorino U, Andreola S, Tagliabue E, et al. Immunocytochemical markers in stage I lung cancer: relevance to prognosis. J Clin Oncol 1997; 15: 2858-2865.

32 Kreuter M, Kropff M, Fischaleck A, et al. Prognostic relevance of angiogenesis in stage III NSCLC receiving multimodality treatment. Eur Respir J 2009; 33: 1383-1388.

33 Meert AP, Paesmans M, Martin B, et al. The role of microvessel density on the survival of patients with lung cancer: a systematic review of the literature with meta-analysis. Br J Cancer 2002; 87: 694-701.

34 Trivella M, Pezzella F, Pastorino U, et al. Microvessel density as a prognostic factor in non-small-cell lung carcinoma: a metaanalysis of individual patient data. Lancet Oncol 2007; 8: 488-499.

35 Onn A, Herbst RS. Angiogenesis and lung cancer: implications for prognosis and treatment. Lancet Oncol 2007; 8: 460-461.

36 Willett CG, Boucher Y, di Tomaso E, et al. Direct evidence that the VEGF-specific antibody bevacizumab has antivascular effects in human rectal cancer. Nat Med 2004; 10: 145-147.

37 Prewett M, Huber J, Li Y, et al. Antivascular endothelial growth factor receptor (fetal liver kinase 1) monoclonal antibody inhibits tumor angiogenesis and growth of several mouse and human tumors. Cancer Res 1999; 59: 5209-5218.

38 Jubb AM, Hurwitz HI, Bai W, et al. Impact of vascular endothelial growth factor-A expression, thrombospondin-2 expression, and microvessel density on the treatment effect of bevacizumab in metastatic colorectal cancer. J Clin Oncol 2006; 24: 217-227.

39 Artacho-Perula E, Roldan-Villalobos R, Cruz-Orive LM. Application of the fractionator and vertical slices to estimate total capillary length in skeletal muscle. J Anat 1999; 195: 429-437.

40 Mancuso MR, Davis R, Norberg SM, et al. Rapid vascular regrowth in tumors after reversal of VEGF inhibition. J Clin Invest 2006; 116: 2610-2621.

41 Tan AR, Yang X, Hewitt SM, et al. Evaluation of biologic end points and pharmacokinetics in patients with metastatic breast cancer after treatment with erlotinib, an epidermal growth factor receptor tyrosine kinase inhibitor. J Clin Oncol 2004; 22: 3080-3090.

42 Cai W, Chen X. Multimodality molecular imaging of tumor angiogenesis. J Nucl Med 2008; 49: Suppl. 2, 113S-128S. 
43 Yuan A, Yu CJ, Chen WJ, et al. Correlation of total VEGF mRNA and protein expression with histologic type, tumor angiogenesis, patient survival and timing of relapse in non-small-cell lung cancer. Int J Cancer 2000; 89: 475-483.

44 Decaussin $\mathrm{M}$, Sartelet $\mathrm{H}$, Robert $\mathrm{C}$, et al. Expression of vascular endothelial growth factor (VEGF) and its two receptors (VEGF-R1Flt1 and VEGF-R2-Flk1/KDR) in non-small cell lung carcinomas (NSCLCs): correlation with angiogenesis and survival. I Pathol 1999; 188: 369-377.

45 Smith NR, James NH, Oakley I, et al. Acute pharmacodynamic and antivascular effects of the vascular endothelial growth factor signaling inhibitor AZD2171 in Calu-6 human lung tumor xenografts. Mol Cancer Ther 2007; 6: 2198-2208.

46 Rak J, Mitsuhashi Y, Bayko L, et al. Mutant ras oncogenes upregulate VEGF/VPF expression: implications for induction and inhibition of tumor angiogenesis. Cancer Res 1995; 55: 4575-4580.

47 Emlet DR, Brown KA, Kociban DL, et al. Response to trastuzumab, erlotinib, and bevacizumab, alone and in combination, is correlated with the level of human epidermal growth factor receptor-2 expression in human breast cancer cell lines. Mol Cancer Ther 2007; 6: 2664-2674.

48 Ferrara N, Gerber HP, LeCouter J. The biology of VEGF and its receptors. Nat Med 2003; 9: 669-676.

49 Ebos JM, Lee CR, Bogdanovic E, et al. Vascular endothelial growth factor-mediated decrease in plasma soluble vascular endothelial growth factor receptor-2 levels as a surrogate biomarker for tumor growth. Cancer Res 2008; 68: 521-529.

50 Soo RA, McKeegan E, Chen CS, et al. The effect of varying doses of ABT-869 on biomarkers of angiogenesis and their correlation with pharmacodynamic outcome. J Clin Oncol 2008; 26: A14535.

51 Yamada K, Hirata T, Fujiwara Y, et al. Phase I dose escalation study and biomarker analysis of E7080 in patients with advanced solid tumors. J Clin Oncol 2008; 26: A3527.

52 Karrison T, Kindler HL, Gandara DR, et al. Final analysis of a multi-center, double-blind, placebo-controlled, randomized phase II trial of gemcitabine/cisplatin (GC) plus bevacizumab (B) or placebo $(\mathrm{P})$ in patients (pts) with malignant mesothelioma (MM). J Clin Oncol 2007; 25: A7526.

53 Janne PA, Wang XF, Krug LM, et al. Sorafenib in malignant mesothelioma (MM): A phase II trial of the Cancer and Leukemia Group B (CALGB 30307). J Clin Oncol 2007; 25: A7707.

54 Kansas GS. Selectins and their ligands: current concepts and controversies. Blood 1996; 88: 3259-3287.

55 Vestweber D. VE-cadherin: the major endothelial adhesion molecule controlling cellular junctions and blood vessel formation. Arterioscler Thromb Vasc Biol 2008; 28: 223-232.

56 Koch AE, Halloran MM, Haskell CJ, et al. Angiogenesis mediated by soluble forms of E-selectin and vascular cell adhesion molecule-1. Nature 1995; 376: 517-519.

57 Witz IP. The involvement of selectins and their ligands in tumorprogression. Immunol Lett 2006; 104: 89-93.

58 Pigott R, Dillon LP, Hemingway IH, et al. Soluble forms of Eselectin, ICAM-1 and VCAM-1 are present in the supernatants of cytokine activated cultured endothelial cells. Biochem Biophys Res Commun 1992; 187: 584-589.

59 Swellam M, Ragab HM, Abdalla NA, et al. Soluble cytokeratin-19 and E-selectin biomarkers: their relevance for lung cancer detection when tested independently or in combinations. Cancer Biomark 2008; 4: 43-54.

60 Guney N, Soydinc HO, Derin D, et al. Serum levels of intercellular adhesion molecule ICAM-1 and E-selectin in advanced stage nonsmall cell lung cancer. Med Oncol 2008; 25: 194-200.

61 van de Stolpe A, van der Saag PT. Intercellular adhesion molecule-1. J Mol Med 1996; 74: 13-33.

62 Gho YS, Kim PN, Li HC, et al. Stimulation of tumor growth by human soluble intercellular adhesion molecule-1. Cancer Res 2001; 61: $4253-4257$.
63 Grothey A, Heistermann P, Philippou S, et al. Serum levels of soluble intercellular adhesion molecule-1 (ICAM-1, CD54) in patients with non-small-cell lung cancer: correlation with histological expression of ICAM-1 and tumour stage. $\mathrm{Br}$ J Cancer 1998; 77: 801-807.

64 Blaschuk OW, Rowlands TM. Cadherins as modulators of angiogenesis and the structural integrity of blood vessels. Cancer Metastasis Rev 2000; 19: 1-5.

65 Peinado H, Olmeda D, Cano A. Snail, Zeb and bHLH factors in tumour progression: an alliance against the epithelial phenotype? Nat Rev Cancer 2007; 7: 415-428.

66 Gory-Faure S, Prandini $\mathrm{MH}$, Pointu $\mathrm{H}$, et al. Role of vascular endothelial-cadherin in vascular morphogenesis. Development 1999; 126: 2093-2102.

67 Giancotti FG, Ruoslahti E. Integrin signaling. Science 1999; 285 1028-1032.

68 Han JY, Kim HS, Lee SH, et al. Immunohistochemical expression of integrins and extracellular matrix proteins in non-small cell lung cancer: correlation with lymph node metastasis. Lung Cancer 2003, 41: 65-70.

69 Brooks PC, Clark RA, Cheresh DA. Requirement of vascular integrin alpha v beta 3 for angiogenesis. Science 1994; 264: 569-571.

70 Sato T, Konishi K, Kimura H, et al. Vascular integrin beta 3 and its relation to pulmonary metastasis of colorectal carcinoma Anticancer Res 2001; 21: 643-647.

71 Singh B, Fu C, Bhattacharya J. Vascular expression of the alpha beta ${ }_{3}$-integrin in lung and other organs. Am J Physiol Lung Cell Mol Physiol 2000; 278: L217-L226.

72 Goon PK, Lip GY, Boos CJ, et al. Circulating endothelial cells, endothelial progenitor cells, and endothelial microparticles in cancer. Neoplasia 2006; 8: 79-88.

73 Lyden D, Hattori K, Dias S, et al. Impaired recruitment of bonemarrow-derived endothelial and hematopoietic precursor cells blocks tumor angiogenesis and growth. Nat Med 2001; 7: 1194-1201.

74 Asahara T, Murohara T, Sullivan A, et al. Isolation of putative progenitor endothelial cells for angiogenesis. Science 1997; 275 964-967.

75 Shi Q, Rafii S, Wu MH, et al. Evidence for circulating bone marrow-derived endothelial cells. Blood 1998; 92: 362-367.

76 Walter DH, Rittig K, Bahlmann FH, et al. Statin therapy accelerates reendothelialization: a novel effect involving mobilization and incorporation of bone marrow-derived endothelial progenitor cells. Circulation 2002; 105: 3017-3024.

77 Mancuso P, Burlini A, Pruneri G, et al. Resting and activated endothelial cells are increased in the peripheral blood of cancer patients. Blood 2001; 97: 3658-3661.

78 Shintani S, Murohara T, Ikeda H, et al. Mobilization of endothelial progenitor cells in patients with acute myocardial infarction. Circulation 2001; 103: 2776-2779.

79 Gill M, Dias S, Hattori K, et al. Vascular trauma induces rapid but transient mobilization of VEGFR2 ${ }^{+} \mathrm{AC} 133^{+}$endothelial precursor cells. Circ Res 2001; 88: 167-174.

80 Urbich C, Dimmeler S. Endothelial progenitor cells: characterization and role in vascular biology. Circ Res 2004; 95: 343-353.

81 Dome B, Timar J, Dobos J, et al. Identification and clinical significance of circulating endothelial progenitor cells in human non-small cell lung cancer. Cancer Res 2006; 66: 7341-7347.

82 Shaked Y, Ciarrocchi A, Franco M, et al. Therapy-induced acute recruitment of circulating endothelial progenitor cells to tumors Science 2006; 313: 1785-1787.

83 Duda DG, Cohen KS, Ancukiewicz M, et al. A comparative study of circulating endothelial cells (CECs) and circulating progenitor cells (CPCs) kinetics in four multidisciplinary phase 2 studies of antiangiogenic agents. J Clin Oncol 2008; 26: A3544.

84 Beerepoot LV, Mehra N, Vermaat JS, et al. Increased levels of viable circulating endothelial cells are an indicator of progressive disease in cancer patients. Ann Oncol 2004; 15: 139-145. 
85 Mancuso P, Colleoni M, Calleri A, et al. Circulating endothelial-cell kinetics and viability predict survival in breast cancer patients receiving metronomic chemotherapy. Blood 2006; 108: 452-459.

86 Beaudry P, Force J, Naumov GN, et al. Differential effects of vascular endothelial growth factor receptor-2 inhibitor ZD6474 on circulating endothelial progenitors and mature circulating endothelial cells: implications for use as a surrogate marker of antiangiogenic activity. Clin Cancer Res 2005; 11: 3514-3522.

87 Ferreira LS, Gerecht S, Shieh HF, et al. Vascular progenitor cells isolated from human embryonic stem cells give rise to endothelial and smooth muscle like cells and form vascular networks in vivo. Circ Res 2007; 101: 286-294.

88 Ozdogu H, Sozer O, Boga C, et al. Flow cytometric evaluation of circulating endothelial cells: a new protocol for identifying endothelial cells at several stages of differentiation. Am J Hematol 2007; 82: 706-711.

89 Aoki M, Yasutake M, Murohara T. Derivation of functional endothelial progenitor cells from human umbilical cord blood mononuclear cells isolated by a novel cell filtration device. Stem Cells 2004; 22: 994-1002.

90 Bergsland EK. When does the presence of the target predict response to the targeted agent? J Clin Oncol 2006; 24: 213-216.

91 Hardwick JS, Yang Y, Zhang C, et al. Identification of biomarkers for tumor endothelial cell proliferation through gene expression profiling. Mol Cancer Ther 2005; 4: 413-425.

92 Reinmuth N, Rensinghoff S, Raedel M, et al. Paracrine interactions of vascular endothelial growth factor and platelet-derived growth factor in endothelial and lung cancer cells. Int J Oncol 2007; 31: 621-626.

93 Mueller MM, Fusenig NE. Friends or foes-bipolar effects of the tumour stroma in cancer. Nat Rev Cancer 2004; 4: 839-849.

94 Lindahl $\mathrm{P}$, Johansson BR, Leveen $\mathrm{P}$, et al. Pericyte loss and microaneurysm formation in PDGF-B-deficient mice. Science 1997; 277: 242-245.

95 Hasumi Y, Klosowska-Wardega A, Furuhashi M, et al. Identification of a subset of pericytes that respond to combination therapy targeting PDGF and VEGF signaling. Int J Cancer 2007; 121: 2606-2614. 